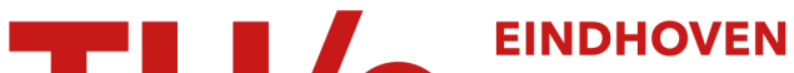 UNIVERSITY OF TECHNOLOGY
}

\section{Particle nucleation-accumulation mode trade-off : A second diesel dilemma?}

Citation for published version (APA):

Reijnders, J. J. E., Boot, M. D., \& de Goey, L. P. H. (2018). Particle nucleation-accumulation mode trade-off : A second diesel dilemma? Journal of Aerosol Science, 124, 95-111. https://doi.org/10.1016/j.jaerosci.2018.06.013

DOI:

10.1016/j.jaerosci.2018.06.013

Document status and date:

Published: 01/10/2018

\section{Document Version:}

Accepted manuscript including changes made at the peer-review stage

\section{Please check the document version of this publication:}

- A submitted manuscript is the version of the article upon submission and before peer-review. There can be important differences between the submitted version and the official published version of record. People interested in the research are advised to contact the author for the final version of the publication, or visit the $\mathrm{DOI}$ to the publisher's website.

- The final author version and the galley proof are versions of the publication after peer review.

- The final published version features the final layout of the paper including the volume, issue and page numbers.

Link to publication

\section{General rights}

Copyright and moral rights for the publications made accessible in the public portal are retained by the authors and/or other copyright owners and it is a condition of accessing publications that users recognise and abide by the legal requirements associated with these rights.

- Users may download and print one copy of any publication from the public portal for the purpose of private study or research.

- You may not further distribute the material or use it for any profit-making activity or commercial gain

- You may freely distribute the URL identifying the publication in the public portal.

If the publication is distributed under the terms of Article $25 \mathrm{fa}$ of the Dutch Copyright Act, indicated by the "Taverne" license above, please follow below link for the End User Agreement:

www.tue.nl/taverne

Take down policy

If you believe that this document breaches copyright please contact us at:

openaccess@tue.nl

providing details and we will investigate your claim. 


\title{
Particle nucleation-accumulation mode trade-off: A second diesel dilemma?
}

\author{
Jos Reijnders*, Michael Boot and Philip de Goey \\ Eindhoven University of Technology, Mechanical Engineering, Combustion Technology, PO Box 513, \\ $5600 \mathrm{MB}$, Eindhoven, The Netherlands
}

\begin{abstract}
Historically, regulators of diesel emissions have formulated their legislation in gravimetric terms (i.e., in $\mathrm{g} / \mathrm{km}$ or $\mathrm{g} / \mathrm{kWh}$ ). This quantitative approach, while arguably valid for gaseous emissions such as $\mathrm{NO}_{x}$, does not appreciate the complexity of particulate matter. More recently, much research, along with new legislation, views particulate matter in a more qualitative way and focuses on such metric as the total particle count and size distribution. While the trade-off in gravimetric particular matter and $\mathrm{NO}_{x}$ is well known as the "diesel dilemma", this study, for the first time, demonstrates that there is also a trade-off in particulate size modes (accumulation-nucleation). To this end, a wide range of fuel properties and engine operating conditions are tested on a dedicated heavy-duty test rig. The main message that can be drawn from the results is that the optima for both the classical and newly presented accumulation-nucleation trade-off appear to be concurrent in nature. This implies that when the position on the curve of any given data point is known for one trade-off, the associated location on the other can be qualitatively predicted. Given the breadth of the operation conditions and fuel properties tested in this study, it would appear that this concurrence, which could help guide engine calibrators and aftertreatment specialists, is quite robust indeed.
\end{abstract}

Keywords: Particle size distribution, particulate matter, $\mathrm{NO}_{x}$, accumulation, nucleation

\section{Introduction}

\subsection{Background}

For decades there have been serious health concerns about diesel engine generated particulate matter (PM). As a result, the relationship between particle size and toxicology has become a key subject of investigation for many researchers [1-4]. The advent of commercially available exhaust mounted particle sizers has been an important catalyst for such studies. In literature, researchers typically report on total particle

\footnotetext{
${ }^{*}$ Corresponding author. Eindhoven University of Technology, PO Box 513, 5600MB, Eindhoven, The Netherlands

Email address: j.j.e.reijnders@tue.nl (Jos Reijnders)
} 
concentration, along with the associated so-called count median diameter (CMD) to characterize the particle size distribution.

Needless to say, both the chemical composition of the fuel and the physiochemical conditions in the combustion chamber will leave their respective marks on the particle size distribution. It is the objective of this paper to examine these relationships both qualitatively and quantitatively for a wide range of fuels and engine operating conditions. Hereby, the scope is confined to what goes into and comes directly out of the engine (Figure 1). The techno-economic viability (TEV) and life cycle assessments (LCA) of the respective fuels thus fall outside the scope of this paper. A detailed study into the efficacy of aftertreatment devices, such as diesel particulate filters (DPF) and selective catalytic reduction (SCR), along with their toxicological effects, will also not be subject of discussion here. Notwithstanding aforementioned limitations, the implications of our main findings in relation to DPF efficacy will be treated briefly in the Discussion section.

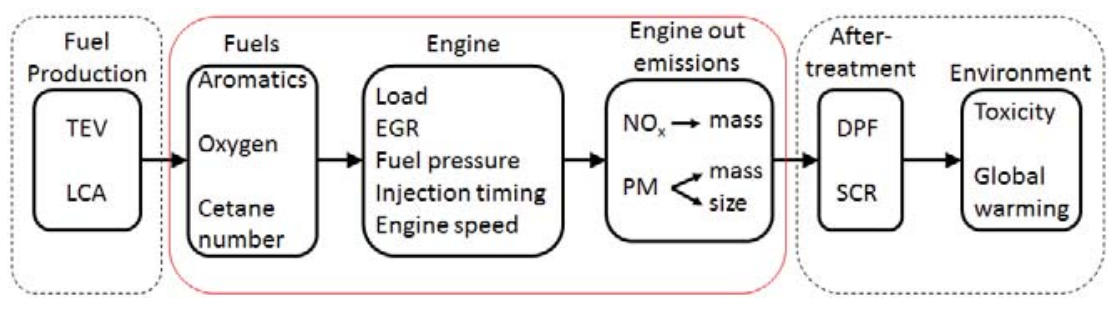

Figure 1: Scope of this study

Until now, engine studies on this topic have been generally confined to one particular fuel property or engine operating variable. The added value of this study is that even five operating variables are considered (load, exhaust gas recirculation (EGR), combustion phasing, injection pressure and engine speed). Moreover, these variables will be pushed to extreme levels, so as to evaluate the effects on particle size distribution in both conventional diesel combustion and so-called low temperature or partially premixed compression ignition modes. The fuel matrix, too, is quite expansive, comprising 18 different fuel blends, spanning a large range in aromaticity (0-30 wt-\%), cetane number $(\mathrm{CN})(15-80)$ and oxygen concentration (0-8 wt-\%).

\subsection{Soot particle evolution}

Particulate matter is a generic term for solids emitted from combustion processes, which may include un- or partially burnt fuel and lubricant oil, water, metals and sulfates [5]. In conventional (i.e., diffusion combustion dominated) compression ignition engines, the formation of PM is a complicated process, whereby unburnt fuel derivatives nucleate from the vapor into the solid phase in the fuel-rich core of the diffusion flame. This conversion can be described by various sequential processes, schematically drawn in Figure 2. This figure, as well as the explanation that follows is a digest of various sources [6-10]. 


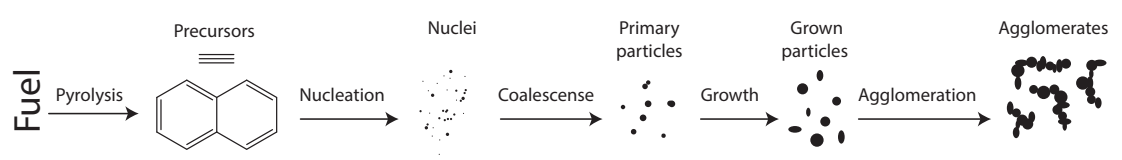

Figure 2: Schematic representation of the particulate matter formation process in diffusion flame-dominated compression ignition combustion processes

\section{Fuel pyrolysis}

Pyrolysis is the process through which fuel molecules decompose to smaller ones (e.g., $\mathrm{C}_{2} \mathrm{H}_{2}$ ) and subsequently recombine to soot precursors (e.g., benzene, $\mathrm{PAH}$ ) under oxygen deprived and high temperature conditions.

\section{Nucleation}

Nucleation is the process where the first noticeable particulates (called nuclei) come into existence by formation of carbon lamella and crystallization of the PAHs. Nuclei itself do not contribute significantly to the total soot mass, although they have an important influence on the mass later due to their high surface area for surface growth.

\section{Coalescence}

Coalescence (also called coagulation) is a process whereby nuclei collide and merge. Accordingly, the number of particulates decreases, while the mass remains more or less the same.

\section{Surface growth}

While the nuclei themselves do not contribute significantly to total soot mass, their presence allows still gaseous PAH and other soot precursors to condense. In fact, such surface growth, while not adding to the total particle count, is responsible for the greater part of emitted particle mass.

\section{Agglomeration}

Agglomeration is also a secondary collision (coalescence) process, which yields chain structures or clusters of particulates.

\section{Oxidation}

Oxidation may occur during any one or more of the aforementioned processes. The oxidation process converts carbon or hydrocarbons to combustion products as $\mathrm{CO}, \mathrm{CO}_{2}, \mathrm{H}_{2} \mathrm{O}$. When carbon is completely oxidized to $\mathrm{CO}_{2}$ or even partially oxidized to $\mathrm{CO}$, it will not evolve into a soot particulate anymore [6]. Importantly, nearly all of the formed particles are oxidated at one point or other, with only a small part slipping through and ending up in the tailpipe.

In the next section, a typical size distribution of the particulates is presented, including a discussion on the effects of the nucleation and accumulation modes on the distribution curve. 


\subsection{Soot particle size distribution}

Figure 3 shows a typical diesel-engine-based particle size distribution (PSD) as can be found in literature [7]. On the horizontal axis, the particle size is plotted on a logarithmic scale because of the typical log-normal nature of the curves in question. On the vertical axis, the particle normalized concentration is plotted, which allows for comparison of results obtained from different types of analytical devices (e.g., with varying resolution, channels) [11].

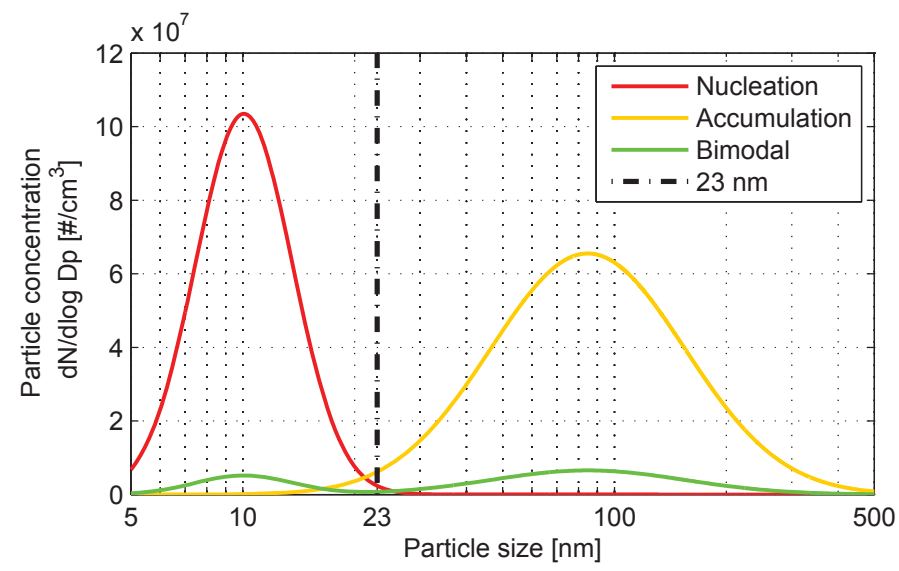

Figure 3: Typical CI engine out PSDs for different modes.

The left and right peaks are related to the nucleation and accumulation modes, respectively. The former mode comprises nuclei with a number median diameter $\left(N M D=D_{p}(N / 2)\right)$ below $20 \mathrm{~nm}$. These particles are normally formed in the premixed combustion zone of a CI diffusion flame or throughout the premixed combustion phase and mainly consist of volatiles (e.g., light HCs and sulfuric acids), but also of solids (e.g., metals and heavy hydrocarbons) [5]. Logically, the volatile nano-droplets are quite sensitive to sampling temperature and diluter settings (explained later in Section 2.1.2).

The accumulation mode on the other hand tends to comprise particles with an NMD ranging from 50 to $200 \mathrm{~nm}$. These particles are typically formed in the rich combustion zone and consist mainly of carbon in the form of PAH. These particles, as explained earlier, start out as nuclei and gradually grow in several steps to larger diameters.

\section{Methodology}

\subsection{Soot measurement techniques}

\subsubsection{AVL $415 \mathrm{~S}$}

Gravimetric particulate emissions will be measured by the AVL 415S smoke meter using the well known filter paper method. The measurement principle of this smoke meter is as follows. A part of the exhaust gas flow is sampled by means of a probe in the exhaust pipe and drawn through filter paper. The resultant blackening of this 
filter is measured by a reflectometer and translated into a so-called filter smoke number (FSN). This number can subsequently be used to calculate the soot mass $\left[\mathrm{mg} / \mathrm{m}^{3}\right]$ by applying the following empirical formula [12]:

$$
P M_{\text {mass }}=4.95 / 0.405 \cdot F S N \cdot e^{(0.38 \cdot F S N)} .
$$

Given that the formula dates back to Euro I era, Northrop et al. [13] reevaluated its validity under more modern operating conditions in 2011 and found it to still be quite accurate, even in the lower range (0.02-1.5 FSN).

\subsubsection{Testo ViPR (Volatile Particle Remover)}

There is a growing interest in particle count and size distributions. The device used to evaluate these qualitative aspects of soot emissions in this study is the engine exhaust particle sizer (EEPS) (Section 2.1.3). Before the PSD can be measured, the exhaust flow needs to be conditioned.

The conditioning apparatus used here is the Testo volatile particle remover (ViPR) which consists of two diluters (MD19-3E \& ASET15-1). A schematic representation of the ViPR setup is shown in the appendix (Figure B.1). There are two reasons to use this device. First, the particle density in the exhaust flow is too high to be measured directly by the EEPS, which makes it necessary to dilute the flow. Second, as discussed earlier, the volatile particles are too sensitive for thermal conditions [14] and therefore need to be removed.

This prompts the question whether this removal still represents the real case. Fushimi et al. [15] performed a study on this topic and found that in the atmosphere, almost no volatile particles are measured and attribute this to likely evaporation of the small particles. Accordingly, it would appear to be fair to remove the volatile particles from the exhaust as well when measuring the PSD.

The ViPR is a two stage diluter, the first stage is a rotating disc and the second stage a thermo-diluter. In Figure 4, a schematic graph is shown which explains the basic idea behind the ViPR. The rotating disc ensures a primary dilution (factor ranging from 15 to 300) at a temperature in the range of $20-150{ }^{\circ} \mathrm{C}$ (path $\mathrm{A} \rightarrow \mathrm{B}$ ). For this work, $150{ }^{\circ} \mathrm{C}$ is used which prevents water to condense in the dilution head and associated tubing. However, some other components (e.g. heavier hydrocarbons) can still condensate.

The flow is then transported to the thermo-diluter, where it is first heated up to $300^{\circ} \mathrm{C}(\mathrm{B} \rightarrow \mathrm{C})$ and subsequently diluted by a factor ranging from 1 to $11(\mathrm{C} \rightarrow \mathrm{D})$. Finally, the flow is cooled down again (path $\mathrm{D} \rightarrow \mathrm{E}$ ). This secondary dilution process ensures that the nano-droplets which already exist in the gas sample (e.g. heavier HCs) at point $\mathrm{B}$, evaporate again. During the route $(\mathrm{C} \rightarrow \mathrm{D} \rightarrow \mathrm{E})$ the compound remains in the vapor phase. Without using the thermo-diluter $(B \rightarrow E)$, the number concentration of the droplets will be reduced, but the nano-droplets formed at B are unable to evaporate, because of a hysteresis effect between condensation and evaporation. Once the volatile particles are removed and the particle concentration is in the correct range, the sample can be transported to the EEPS. 


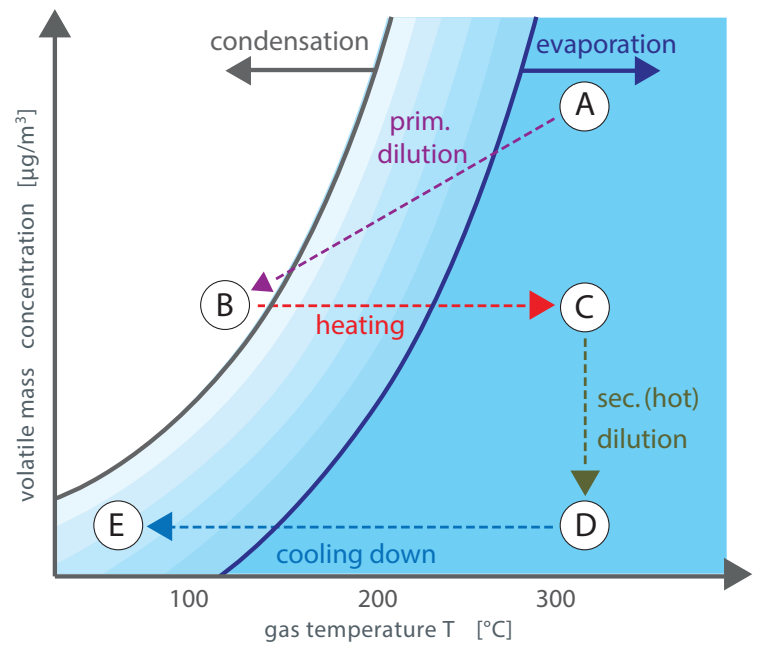

Figure 4: Volatile mass diagram of the Testo ViPR [Reproduced with permission of Testo GmbH]

The settings of the diluters used in this work can be found in Table 1.

Table 1: ViPR and EEPS settings

\begin{tabular}{lll}
\hline Primary diluter: & & \\
Temperature & {$\left[{ }^{\circ} \mathrm{C}\right]$} & 150 \\
Dilution ratio & {$[-]$} & 50 \\
\hline Secondary diluter: & & \\
Temperature & {$\left[{ }^{\circ} \mathrm{C}\right]$} & 300 \\
Dilution ratio & {$[-]$} & 6.7 \\
\hline EEPS: & & \\
Matrix & {$[-]$} & Soot \\
Duration & {$[\mathrm{s}]$} & 60 \\
\hline
\end{tabular}

\subsubsection{TSI Engine Exhaust Particle Sizer (EEPS)}

Once the exhaust sample is conditioned and diluted by the ViPR, the PSD can be determined by the Engine Exhaust Particle Sizer (EEPS). The EEPS is a well-established instrument in aerosol science [16] and therefore details on the working principle thereof will not be provided here.

The detection range of the EEPS for the particle concentration is dependent on the particle size. In Figure 5, the minimum and maximum concentration limits are shown. For all the measurements preformed in this study, the concentration was well between the two limits. During this work the "soot" inversion matrix is used (Table 1). 


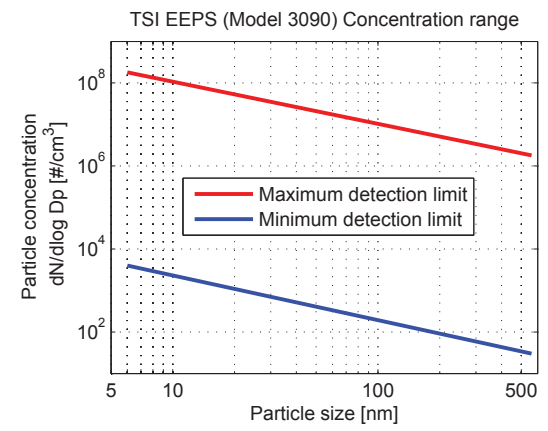

Figure 5: Concentration limits of the particle number of the EEPS.

\subsection{Experimental setup}

The experiments are performed on a 12.6 litre heavy duty (HD) DAF XE 355C in-line six cylinder CI, the specifications of which can be found in Table 2), with more detailed information available elsewhere [17]. Figure 6 shows a schematic overview of the test engine. Importantly, the first cylinder, used as test cylinder, is equipped with dedicated in- and outlet manifolds, EGR circuit and fuel injection system.

Table 2: Engine specifications

\begin{tabular}{ll}
\hline Type & 6-cylinder HDDI CI \\
Model & DAF XE355C \\
Cylinders & 6, with 1 isolated for research \\
Capacity [1] & 12.6 \\
Bore [mm] & 130 \\
Stroke [mm] & 158 \\
Compression ratio [-] & 15.7 \\
\hline
\end{tabular}

Air for the test cylinder is provided using an external air compressor (up to 5 bar). Air mass flow is measured by a Coriolis mass flow meter. The fuel injection system comprises a Resato double-acting air-driven fuel pump (up to 2500 bar) and a prototype common rail injector with 8 holes of $0.151 \mathrm{~mm}$. The first cylinder thus operates autonomously from the rest of the otherwise stock engine, save for its shared cam- and crankshafts, and lubricating and cooling systems.

Several surge tanks have been installed to allow for more homogeneous mixing of air and EGR. The EGR system itself is equipped with a cooler to bring down the gas temperature to approximately the ambient level of $300 \mathrm{~K}$. Concerning the other cylinders in this configuration, numbers 2 and 3 are not fired, and the remaining ones are operated by the stock engine control unit (ECU) and are responsible for setting and maintaining the desired engine speed. 


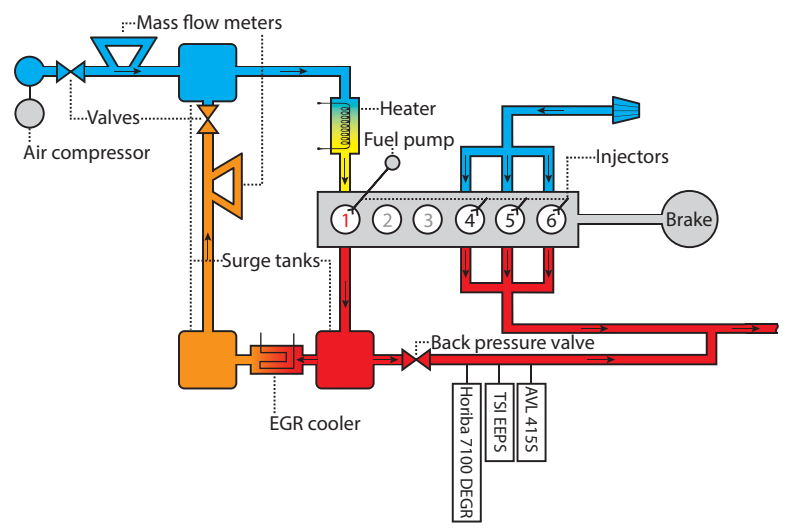

Figure 6: Schematic overview of the test engine

Emissions are recorded by a total of three systems. The PM mass and number is measured by the AVL smoke meter and TSI EEPS, respectively, as explained in section 2.1. For each operating point, exhaust smoke level is averaged over three measurements and the particle size distribution is measured at $10 \mathrm{~Hz}$ and averaged over 60 seconds. Finally, a Horiba Mexa 7100 DEGR is used for gaseous exhaust emissions, namely $\mathrm{O}_{2}, \mathrm{NO}_{x}, \mathrm{HC}, \mathrm{CO}, \mathrm{CO}_{2}$ (intake) and $\mathrm{CO}_{2}$ (exhaust). These gaseous emissions, along with all common pressure, temperature and mass flow sensors are each logged for 40 seconds at $20 \mathrm{~Hz}$ at each operating point. Conditions in the test cylinder are monitored by a SMETEC Combi crank angle (CA) resolved data acquisition system. This data is logged, using a resolution of $0.1 \mathrm{CA}$ degree over a period 50 consecutive cycles. Variables recorded by this system include in-cylinder (AVL GU21C), intake and fuel rail pressure, as well as injector current.

\subsection{Fuel matrix}

The diverse nature of the fuel matrix used in this study results from the fact that it has been built up from various smaller fuel matrices from earlier projects conducted on the same engine setup. Grouped into three main categories, as itemized below, the 18 fuel blends considered here were selected such in order to span a wide range in aromaticity (0-30 wt-\%), CN (15-80) and fuel oxygen (0-8 wt-\%) (Table 3).

- Diesel blends: diesel + 10 vol-\% ML / EL / FEE / ETE (see Table 3 for meaning abbreviations).

- Heptane blends: heptane + toluene $(5 \mathrm{vol}-\%)$ / anisole or methoxybenzene (5, $10,20 \mathrm{vol}-\%)$ / veratrole or 1,2-dimethoxybenzene (5, 10, 20 vol-\%).

- GTL/gasoline blends: 100/0, 90/10, 80/20, 50/50 and 0/100 vol-\%. 


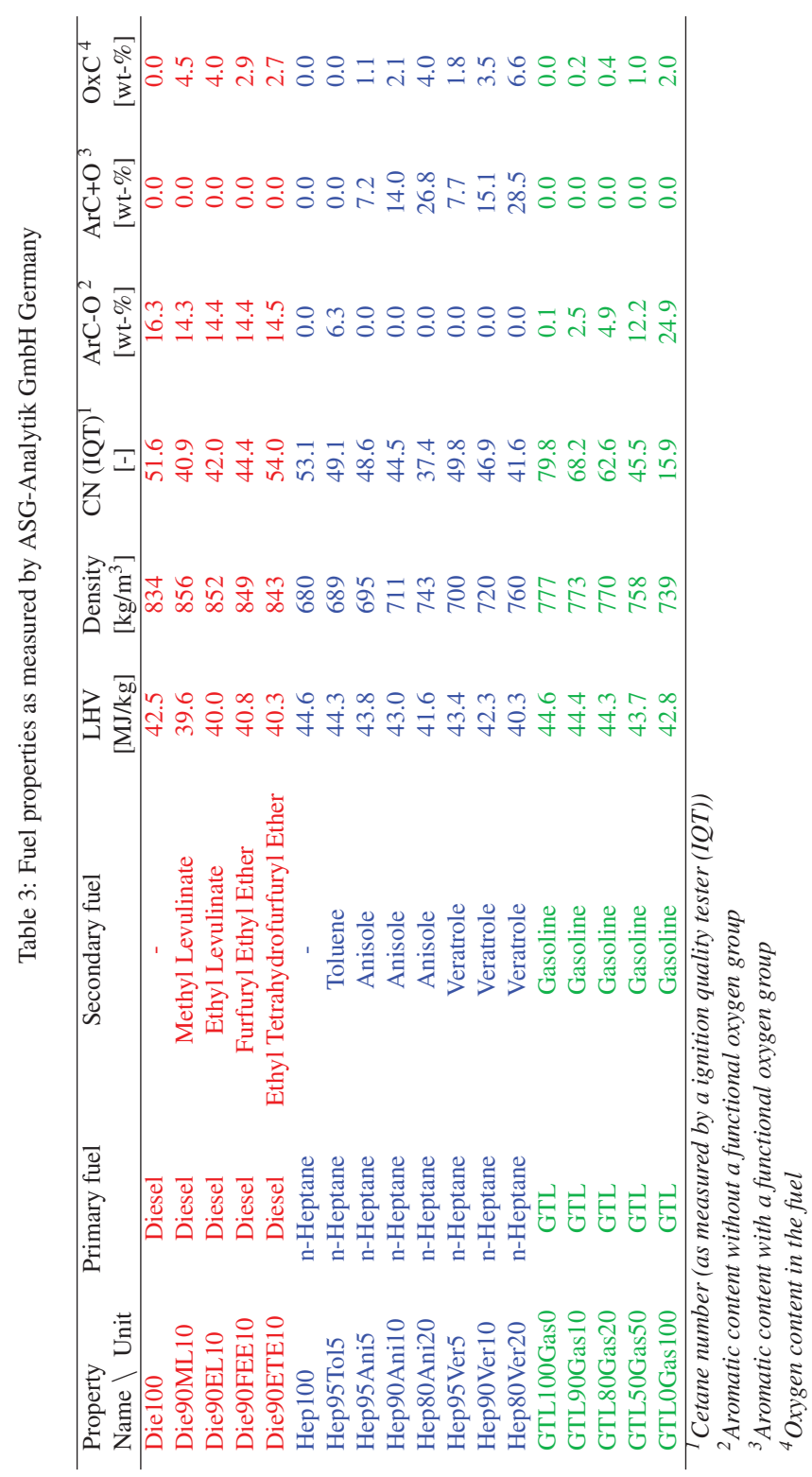

9 


\subsection{Experimental procedure}

Prior to each experimental cycle, the engine has to run stable at steady-state conditions, characterized here by lubrication oil and coolant temperatures of 90 and $85^{\circ} \mathrm{C}$, respectively. In all cases, a single injection per cycle is used. While multiple injections are common in modern engines, the use of this strategy here would unnecessarily complicate the analysis on our main research objective.

Safeguarding for a fair comparison between the various experiments, combustion phasing, defined here as CA50, the crank angle where 50\% heat is released, is held constant at $10{ }^{\circ} \mathrm{CA}$ after top dead centre (TDC). This fixation is realized in practice by varying the start of injection (SOI). The parameter of interest is "sweeped" from the lower to the upper limit, typically in 10 steps, whilst all other parameters are kept at their respective default values. The measurements are performed under steady-state conditions, which in practice requires at least 2 minutes of constant engine operation. A summary of the base and varied values of the operation conditions is shown in Table 4.

Table 4: Operating conditions

\begin{tabular}{llcc}
\hline Parameter & Unit & Base case & Sweeps \\
\hline IMEP $_{g}$ & {$[\mathrm{bar}]$} & 6 & $4-11$ \\
EGR & {$[\mathrm{wt} . \%, \mathrm{CO} 2 / \mathrm{CO} 2]$} & 0 & $0-50$ \\
Injection pressure & {$[\mathrm{bar}]$} & 1500 & $400-1800$ \\
CA50 & {$[\mathrm{CAD}$ aTDC $]$} & 10 & $0-18$ \\
Engine speed & {$[\mathrm{RPM}]$} & 1200 & $800-1800$ \\
Intake pressure & {$[\mathrm{bar}]$} & 1 & \\
Exhaust pressure & {$[\mathrm{bar}]$} & 1.3 & \\
Intake temperature & {$\left[{ }^{\circ} \mathrm{C}\right]$} & 40 & \\
Lambda $(\lambda)$ & {$[-]$} & $1.2-3^{5}$ & \\
\hline 5 & &
\end{tabular}

For the IMEP, EGR and injection pressure sweeps, variation of a single parameter was sufficient for a transition from near-zero (in $\mathrm{g} / \mathrm{kWh}$ ) to excessive PM levels. The same wide range in PM emissions could not be achieved by varying CA50 or engine speed alone. To nevertheless still accomplish aforementioned transition for these parameters, some additional engine settings had to be changed concurrently in accordance with Tables 5 and 6. 
Table 5: Operating conditions CA50 sweep

\begin{tabular}{ccc}
\hline$\#$ & IMEP $_{g}$ [bar] & EGR [wt.\%] \\
\hline 1 & 6 & 0 \\
2 & 6 & 30 \\
3 & 10 & 30 \\
\hline
\end{tabular}

Table 6: Operating conditions speed sweep

\begin{tabular}{ccc}
\hline$\#$ & IMEP $_{g}$ [bar] & EGR [wt.\%] \\
\hline 1 & 4 & 0 \\
2 & 6 & 0 \\
3 & 8 & 0 \\
4 & 8 & 15 \\
5 & 8 & 30 \\
\hline
\end{tabular}

\section{Results and discussion}

From Section 1.3, it is known that there is a relationship between PM nucleation and accumulation modes, typically characterized by particles smaller and larger than $23 \mathrm{~nm}$, respectively. In Figure 7, the accumulation mode is plotted against the nucleation mode for all experiments. Data in this figure comprises results from 18 different fuels and over 500 individual operating points, with varying load, EGR, injection pressure, SOI and engine speed.

The well-known soot- $\mathrm{NO}_{x}$ trade-off is now joined by one balancing nucleation and accumulation particles. Moreover, Figure 7 would suggest that this new dilemma is equally challenging, as there appears no combination of fuel and operating conditions manifested in concurrent near-zero values of both PM types. In order to acquire a more firm understanding of this trade-off, the various data sets underpinning Figure 7 will be scrutinized in the following sections. First, associated $\mathrm{PM}-\mathrm{NO}_{x}$ trade-offs are discussed, followed up by a treatise on the accumulation-nucleation trade-offs. 


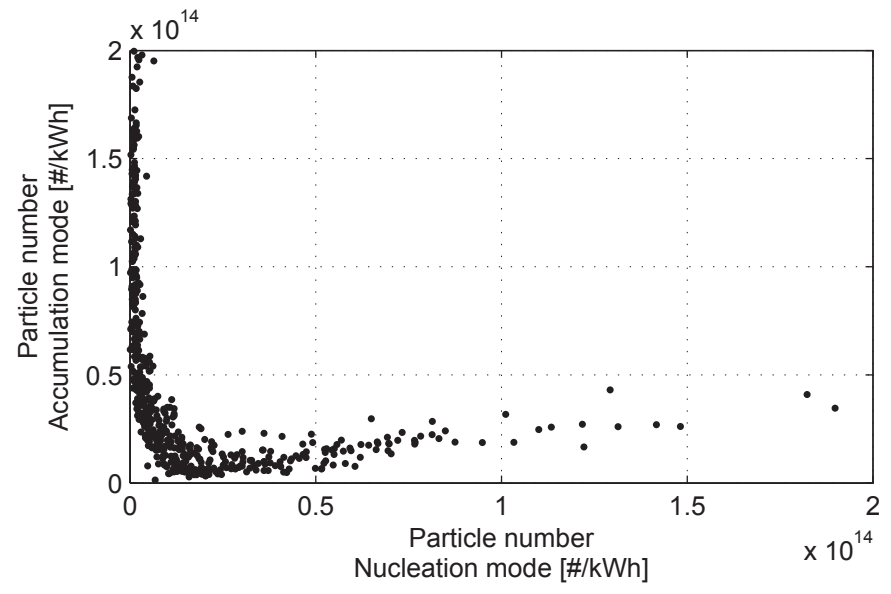

Figure 7: Accumulation mode vs. nucleation mode for all experiments

\subsection{PM vs. $N O_{x}$}

Figure 8 depicts the $\mathrm{PM}-\mathrm{NO}_{x}$ trade-offs collected for all fuels (Table 3 ) and obtained from conducting various sweeps in operating conditions (Table 4 - 6). As is apparent for all curves in Figure 8, there exists a pronounced classical CI trade-off between soot and $\mathrm{NO}_{x}$ emissions. A general observation that can be distilled from these figures, irrespective of fuel identity, is that when mixing conditions become less optimal, as might be expected when decreasing lambda (higher load, EGR), inhibiting air entrainment (lower injection pressures) and allowing less time for mixing (higher engine speeds), soot emissions tend to rise while $\mathrm{NO}_{x}$ falls.

In the associated legends, each individual fuel is denoted by a unique combination of marker color and symbol. The arrows presented in the graphs are indicative of the direction of the sweeps. Where data is available for all fuels (load, EGR and fuel pressure sweeps), a clear and consistent ranking amongst the three aforementioned fuel groups emerges. In all cases, diesel and GTL blends, which show comparable behavior, are outperformed by those having heptane as a base fuel. Furthermore, fuel identity is not equally manifested in all sweeps. For instance, fuel divergence appears more pronounced for the load sweep than in the EGR and injection pressure sweeps. 


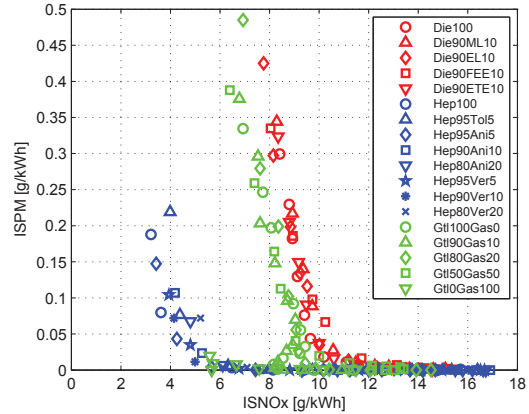

(a) Load (4-11 bar IMEP)

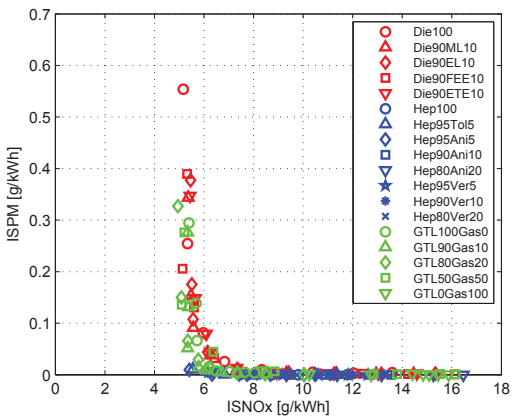

(c) Injection pressure (400 - 1800 bar)

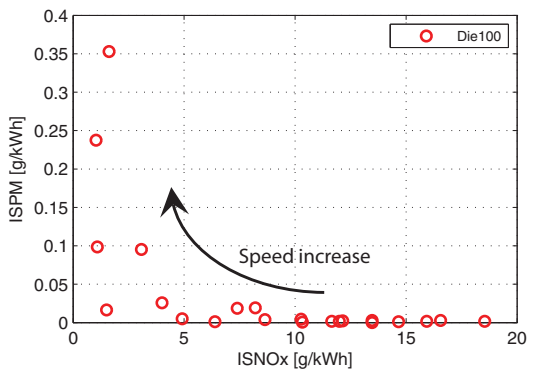

(e) Engine speed (800-1800 RPM)

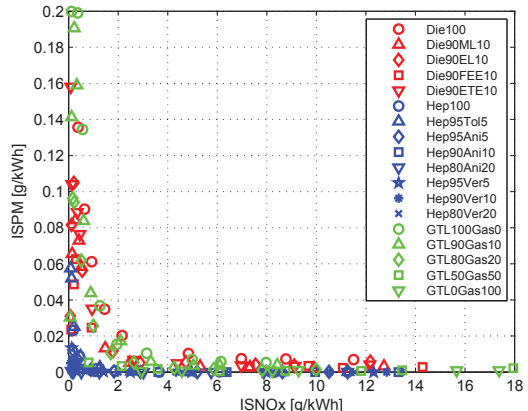

(b) EGR (0 - 50 wt. \%)

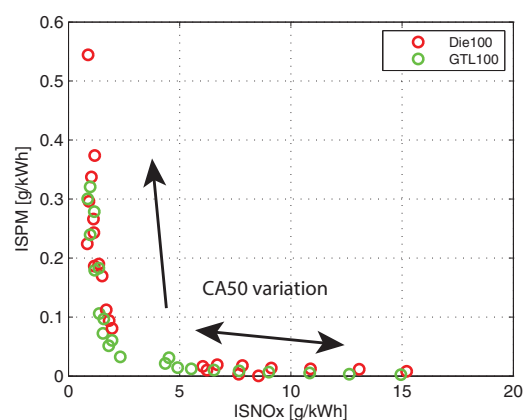

(d) CA50 (0-18 CADaTDC)

Figure 8: $\mathrm{PM}-\mathrm{NO}_{x}$ trade-offs for various fuels and sweeps in operating conditions

As discussed at length in an earlier study [17], for any given fuel, keeping all other variables constant, the proximity of its $\mathrm{PM}-\mathrm{NO}_{x}$ curve to the origin weighs heavily on the prevailing ID and concentration of fuel borne PM precursors. The ID and concentration of PM precursors, in turn, is a function of fuel $\mathrm{CN}$ and aromaticity, respectively. The most favorable trade-offs are to be expected for those fuels having both a low $\mathrm{CN}$ and aromaticity [17]. Note that aromaticity is confined here to non-oxygenated species alone, as earlier research on the same engine has demonstrated markedly lower 
PM emissions for oxygenate aromatics such as those found in various heptane blends (anisole and veratrole) [18].

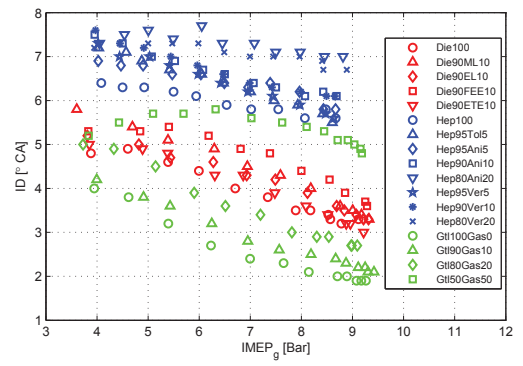

(a) ID vs. load

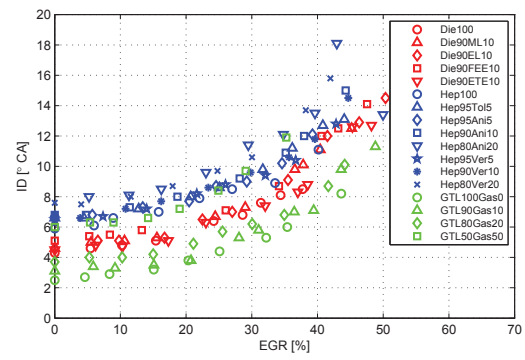

(b) ID vs. EGR

Figure 9: IDs for various fuels during load and EGR sweep.

Figures $9 \mathrm{a}$ and $9 \mathrm{~b}$ show ID for all fuels as a function of load and EGR, respectively. Notwithstanding comparable CN levels (Table 3), the heptane blends yield markedly longer delays than are seen for the diesel blends in both the load and EGR sweeps. As the CN data in Table 3 would suggest, the GTL blends have IDs that are even shorter. What is more, heptane blends also have, by far, the lowest concentration of non-oxygenated aromatics of the three fuel clusters. The highest levels of these compounds are found in the diesel blends. The GTL blends rank in the middle with respect to non-oxygenated aromaticity.

Assuming the above rationale, one would thus expect the best results for the heptane blends as this class is characterized by both a long ID and low aromaticity. For the diesel and GTL blends this relation is not that trivial. The former has low CN but high aromaticity, and the latter has high $\mathrm{CN}$ and low aromaticity. Looking now at the actual $\mathrm{PM}-\mathrm{NO}_{x}$ results in Figure 8, it is clear that the heptane blends, whenever included in the sweep, indeed outperform the other two fuel groups. The remaining two fuel groups, based on diesel and GTL, yield comparable curves, with the exception of load, which suggests that the drawback of high aromaticity of the former fuel is balanced by that of the high $\mathrm{CN}$ of latter. This observation is in agreement with the conclusions from an earlier study [17]. 


\subsection{PM accumulation vs. nucleation}

The PM accumulation-nucleation trade-offs, obtained during these same series of experiments as were conducted for the soot- $\mathrm{NO}_{x}$ plots in the previous section, are plotted in Figure 10. Recall that all data in this figure falls more or less on the same trend line, as shown earlier in Figure 7. As is apparent for all curves in Figure 10, there exists pronounced trade-offs between the PM modes.

It was reported earlier, when discussing the trends in Figure 8, that less optimal mixing conditions tend to manifest in higher soot emissions and lower $\mathrm{NO}_{x}$. From Figure 10 can be observed that when mixing is poor, the accumulation mode tends to rise while the nucleation mode falls. Accordingly, it would appear that a dominant accumulation mode coincides with high and low gravimetric $\mathrm{PM}$ and $\mathrm{NO}_{x}$ emissions, respectively. The opposite tends to hold whenever the nucleation mode is the more pronounced of the two.

Interestingly, the same weak, yet consistent ranking amongst the three fuel types seen in Figure 8 holds for Figure 10 as well, whereby the data for the heptane blends is again nearest the origin. Unlike what was seen in the $\mathrm{PM}-\mathrm{NO}_{x}$ trade-offs in Figure 8, however, no discernible advantage is visible for the GTL over diesel blends. 


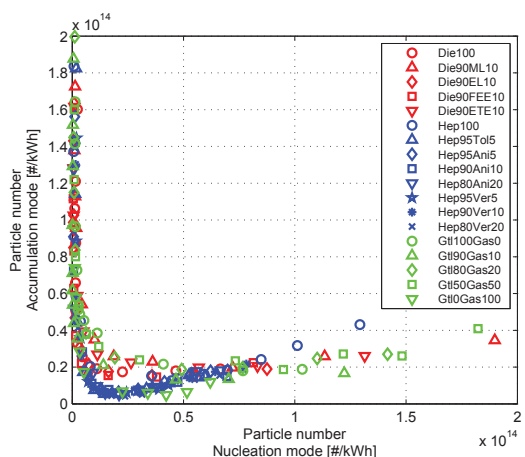

(a) Load (4-11 bar IMEP)

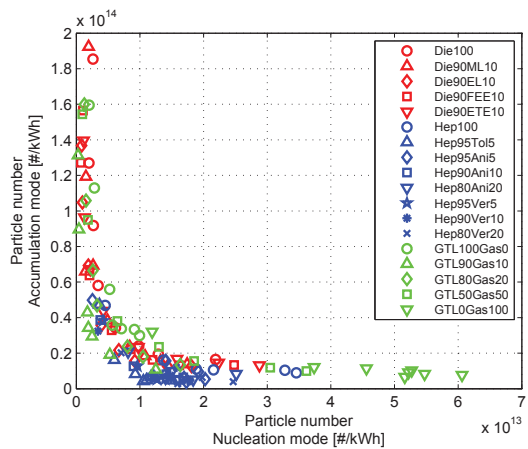

(c) Injection pressure (400 - 1800 bar)

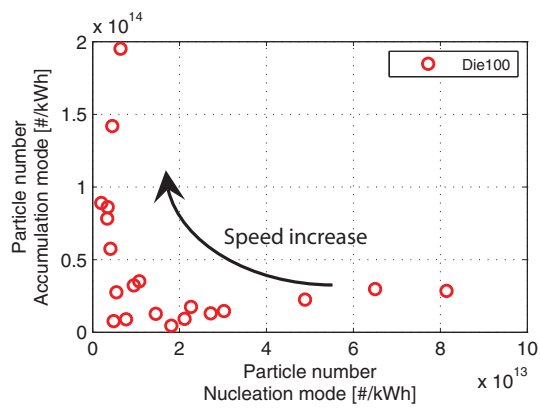

(e) Engine speed (800-1800 RPM)

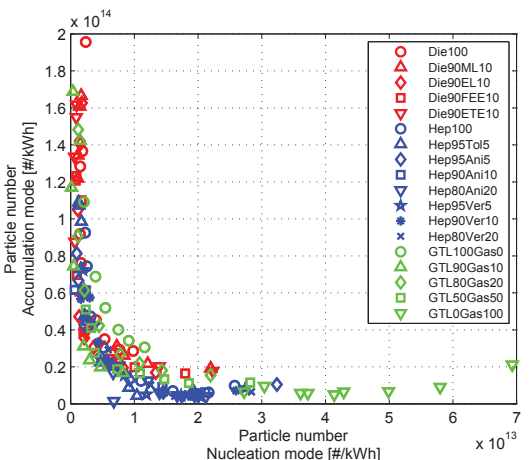

(b) EGR (0 - 50 wt. \%)

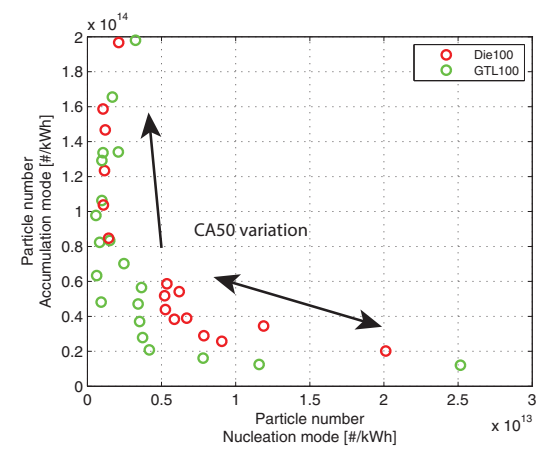

(d) CA50 (0-18 CADaTDC)

Figure 10: PM nucleation-accumulation trade-offs for various fuels and sweeps in operating conditions. NB $\mathrm{x}$-axis range is not constant. 


\subsection{Correlations between trade-offs}

In previous paragraph it became clear that the well-known $\mathrm{PM}-\mathrm{NO}_{x}$ trade-off shows some correlation with a second emissions trade-off, namely one between accumulation and nucleations PM. In this paragraph, a possible causality between these two tradeoffs will be investigated. This is accomplished by overlaying the gravimetric values of both $\mathrm{PM}$ and $\mathrm{NO}_{x}$ to each data point in the accumulation-nucleation figure in the expression of Euro norms (Table 7).

Table 7: Values Euro-norms $\mathrm{PM}$ and $\mathrm{NO}_{x}$

\begin{tabular}{ccc}
\hline $\begin{array}{c}\text { Euro } \\
\text { norm }\end{array}$ & $\begin{array}{c}\text { PM values } \\
{[\mathrm{g} / \mathrm{kWh}]}\end{array}$ & $\begin{array}{c}\mathrm{NO}_{x} \text { values } \\
{[\mathrm{g} / \mathrm{kWh}]}\end{array}$ \\
\hline I & $0.15-0.36$ & $7-8$ \\
II & $0.10-0.15$ & $5-7$ \\
III & $0.02-0.10$ & $3.5-5$ \\
IV & $0.01-0.02$ & $2-3.5$ \\
V & $0.01-0.02$ & $0.4-2$ \\
VI & $<0.01$ & $<0.4$ \\
\hline
\end{tabular}

\subsubsection{Gravimetric PM vs. nucleation-accumulation modes}

From Figure 11 may be inferred that, irrespective of engine operation conditions or fuel properties, the position of any arbitrary data point on the PM accumulationnucleation trade-off can be qualitatively predicted quite well by the associated gravimetric PM Euro norm.

Indeed, compliance with the lower and higher Euro norms tends to coincide with negligible amounts of nucleation and accumulation PM modes, respectively. Unfortunately, as the word trade-off would imply, negligible amounts of either mode coincides with excesses in the other. Importantly, most results nearest the origin, i.e., concurrently low emissions of both accumulation and nucleation mode PM, are found for those data points which also yielded the lowest (i.e., Euro VI) levels of gravimetric PM.

While it is true that the optimum in the trade-off in Figure 11 occurs at Euro VI PM levels, the worst results, pertaining to nucleation mode PM, are found at this norm as well. Indeed, the position on the trade-off curve gradually shifts from a peak in accumulation (at Euro I \& II) to one in nucleation mode (at Euro VI) with tighter gravimetric PM legislation. Given the wide range of fuel properties and operating conditions represented by our data, the validity of this trend is assumed to be quite robust.

An important implication of Figure 11 is thus that a further cut in gravimetric PM levels could lead to an unacceptably high number of the ultra-fine nucleation mode particles. Accordingly, while PM legislation has had a positive effect on both the quantitative as well the qualitative PM thus far, even stricter norms would probably result in an increase in nucleation mode particles. More details on the relation between PM mass and number is given in Appendix C. 


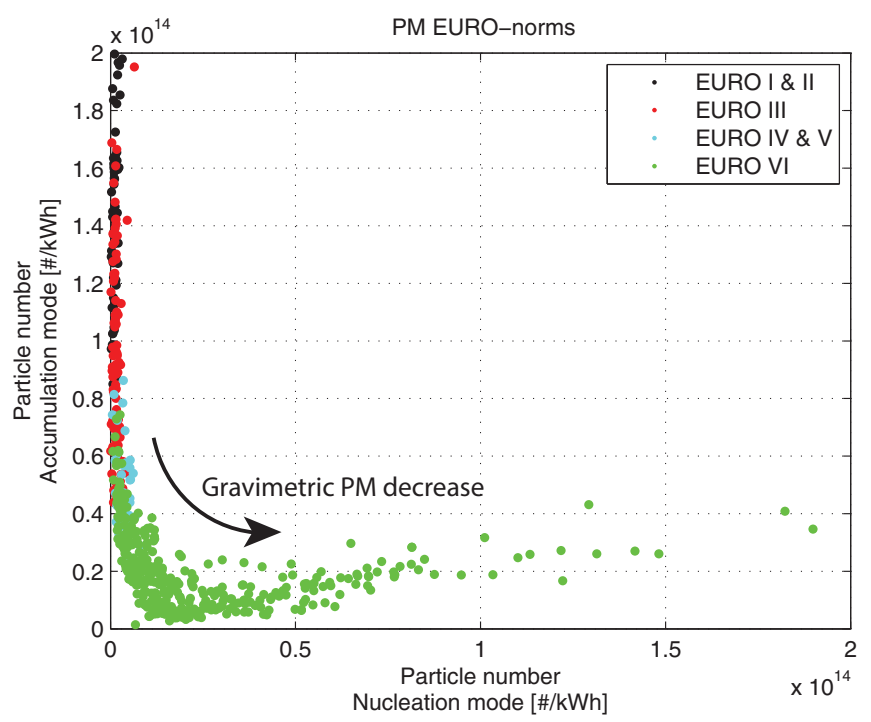

Figure 11: PM nucleation-accumulation trade-off data shown together with associated PM Euro norms

\subsection{2. $N O_{x}$ vs. nucleation-accumulation modes}

Turning now to $\mathrm{NO}_{x}$, Figure 12 depicts the associated emission norms of the PM accumulation-nucleation trade-off data. It is evident that nearly all nucleation mode PM coincides with high $\mathrm{NO}_{x}$ emissions (Euro I \& II). Besides that, there does not appear to be any further $\mathrm{NO}_{x}$ correlation in the data. 


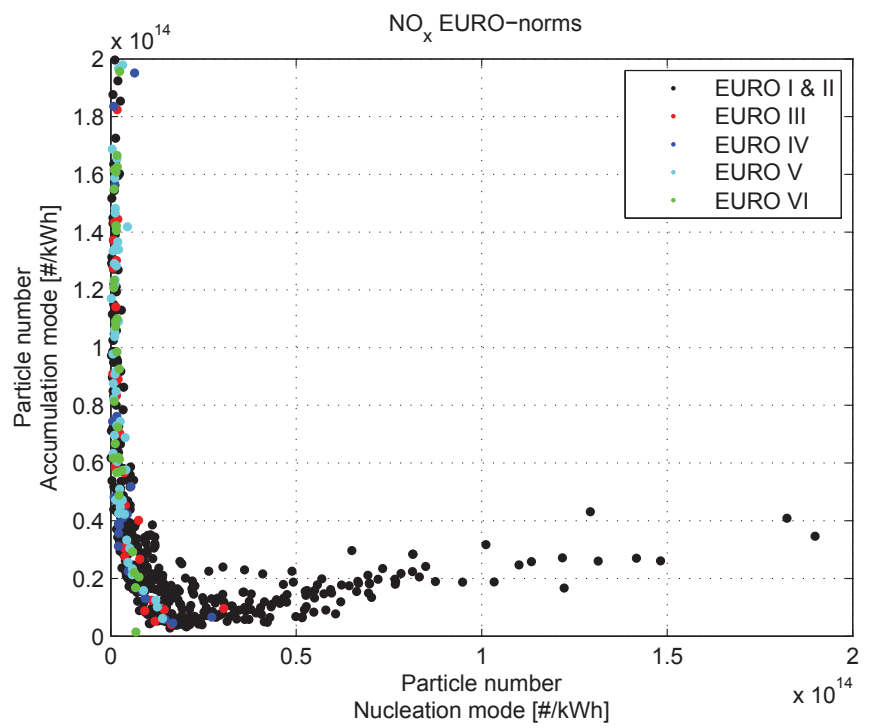

Figure 12: PM nucleation-accumulation trade-off data shown together with associated $\mathrm{NO}_{x}$ Euro norms

\subsubsection{Gravimetric $P M-N O_{x}$ vs. nucleation-accumulation modes}

To continue, Figure 13 shows the combined Euro level for both gravimetric PM and $\mathrm{NO}_{x}$ for each of the data points on the accumulation-nucleation curve. An important observation here is that the worst excesses, pertaining to both accumulation and nucleation mode PM, are found for the lower norms (Euro I - III).

Another important conclusion that may be drawn here is that those data points, which satisfy Euro VI requirements, also yield concurrent low nucleation and accumulation mode particles. 


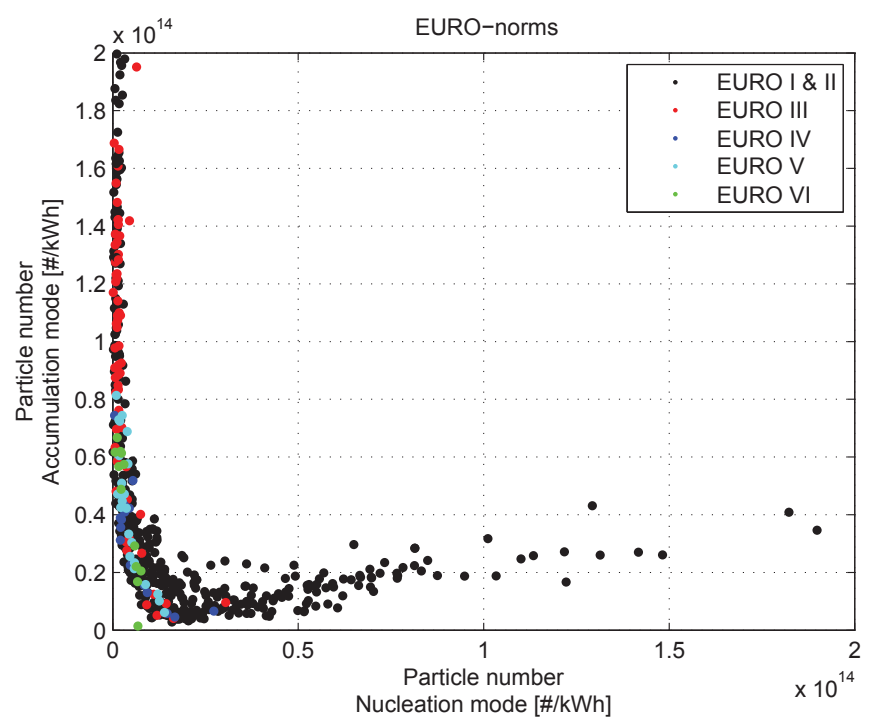

Figure 13: Accumulation mode as function of nucleation mode. Colors indicates the Euro-norms (both PM and $\mathrm{NO}_{x}$ ).

\subsection{Impact of molecule structure on fuel properties}

To study this finding in more detail, Figure 14 zooms in on the relevant area of Figure 13, thereby focussing only on those fuels meeting Euro VI targets.

It is evident from Figure 14 that all the fuels that satisfy Euro VI norms are based on $n$-heptane, albeit with varying concentrations of distinct aromatic oxygenates. What is further striking here is that neat n-heptane does not meet the Euro VI threshold. A final observation concerns the apparent grouping of aromatic oxygenates blended to a specific ratio. In other words, irrespective of type of aromatic oxygenate, those nheptane blends containing 5, 10 or 20 volume percent of either aromatic compound are clustered in accordance with their respective blend aromaticity.

With respect to the operating conditions, it is noteworthy to mention that all (Euro VI) measurement points are achieved in combination with EGR; this for the simple reason that (engine-out) $\mathrm{NO}_{x}$ limits could not be met by any other means. The EGR levels range from $30-45 \%$. The combustion phasing (CA50) is mainly responsible for the efficiency, with the highest values generated at 5-10 CAD aTDC. Concerning fuel pressure, the location on the accumulation-nucleation mode trade-off can be well regulated by this parameter, whereby higher pressure manifest in more nucleation mode particles.

Figure 15 depicts the most important fuel parameters studied in this work. Note that only the solid blue markers satisfy the Euro VI norms.

At a first glance, there appears to be no $\mathrm{CN}$-aromaticity rationale for the better performance of these blends. Notwithstanding an equal aromaticity and $\mathrm{CN}$, for ex- 


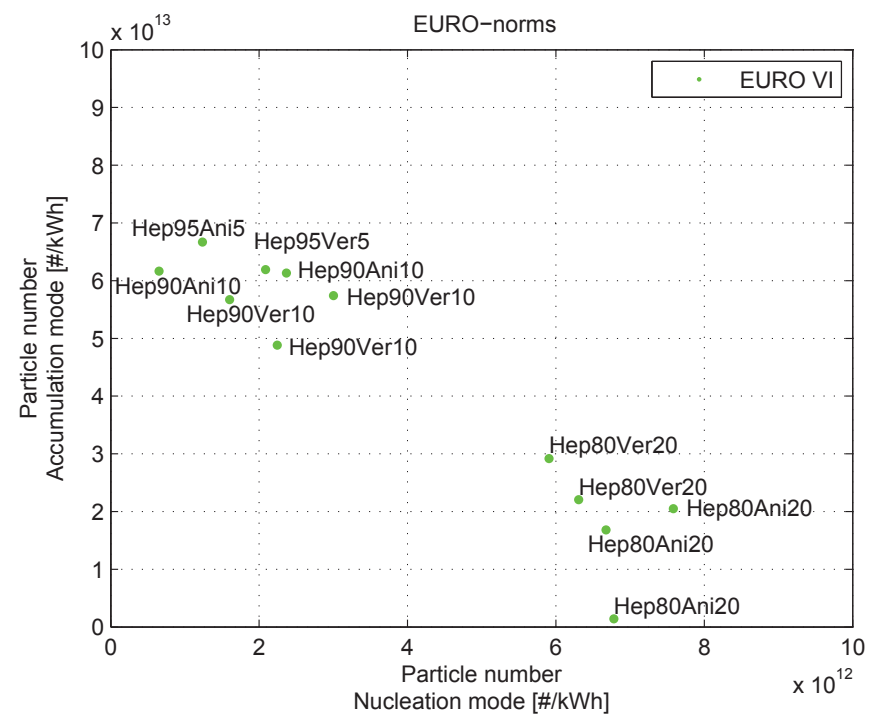

Figure 14: Zoom-in of acc-nucl trade-off (Figure 13). All measurement points satisfy Euro VI norms for PM and $\mathrm{NO}_{x}$.

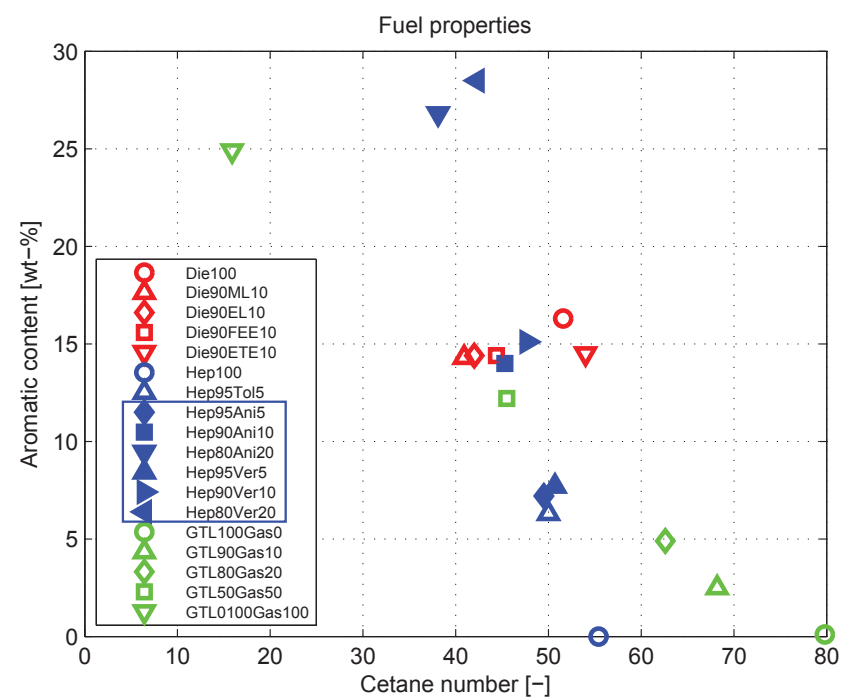

Figure 15: Aromatic content versus cetane number for all the fuels studied in this work. The solid markers correspond to those data points satisfying the Euro VI norms. 
ample Die90FEE10 and Hep90Ani10, Hep95Tol5 and Hep95Ani5, or, Hep95Tol5 and Hep95Ver5, blends containing n-heptane and aromatic oxygenates consistently outperform all other fuels.

A possible explanation for this distinctive behavior may be found in the nature of the aromaticity in question. Aromaticity in the underperforming blends is nonoxygenated, while that in the best performing blends is oxygenated. It is well-known from earlier in-house research [19] that, contrary to what is the case for non-oxygenated aromatics, the oxygenated variant tend to no longer act as soot precursors.

However, other fuels void of any soot precursors (Hep100 and GTL100Gas0) do not meet the Euro VI emission limits either. Arguably, here the high CN appears to be the handicap. Accordingly, optimal performance in both trade-offs is secured only by those fuels having both a low amount of soot precursors and a $\mathrm{CN}$ below, according to this data at least, 51. Whether or not there exists a lower limit of the $\mathrm{CN}$ cannot be concluded from these results.

\section{Discussion}

\subsection{Adsorption of volatiles and nuclei}

Figure 11 shows a strong correlation between the number of large (agglomeration) and small (nucleation) particles. This correlation suggests that the particle modes are mutually exclusive. For higher gravimetric quantities of particles. Another important observation from the same figure is that predominant accumulation and nucleation modes coincide with high and low gravimetric particle emissions, respectively. To better understand the underlying physiochemical mechanism, a brief literature study has been conducted on the topic, with the findings summarized in Table 8 .

A critical parameter cited in most studies is the (average) particle surface area. Adsorption of nuclei of precursors thereof, notably poly-aromatic hydrocarbons (PAH), is reportedly more likely for larger particles, which have commensurately greater surface areas (Figure 16). As a result, the number of large particles relative to small ones will increase.

The opposite trend is observed in modern engines that are compliant with more stringent particle emission legislation. Hereby, large particles are scarcely formed, resulting in a greater amount of volatiles ultimately maturing into nuclei, as well as more nuclei surviving the combustion cycle and ending up in the exhaust system. 
Table 8: Literature overview of adsorption theory

\begin{tabular}{|c|c|}
\hline Ref. \# & Key findings \\
\hline$[20]$ & $\begin{array}{l}\text { Nanoparticle formation may be more likely with clean, low carbon emission engines, espe- } \\
\text { cially when the concentration of carbon has been reduced more markedly than that of particle } \\
\text { precursors. The carbonaceous agglomerates may be thought of as sponges that soak up volatile } \\
\text { particle precursors and prevent them from reaching the level of super-saturation necessary to } \\
\text { produce nucleation. }\end{array}$ \\
\hline [21] & $\begin{array}{l}\text { Older engine designs that emit higher concentrations of carbonaceous agglomerates have large } \\
\text { surface areas available for adsorption of volatile materials. This will tend to prevent saturation } \\
\text { ratios from going high enough to trigger nucleation. On the other hand, with newer designs in } \\
\text { which the carbonaceous component has been removed more effectively than volatiles, there is } \\
\text { little surface area available for the adsorption of these volatiles. This drives saturation ratios } \\
\text { higher and makes nucleation more likely. The lack of carbonaceous material surface area } \\
\text { in modern diesel engines for adsorption of volatile compounds may allow saturation ratios to } \\
\text { become high enough to favor nucleation and the creation of a large nanoparticle number mode. }\end{array}$ \\
\hline$[22]$ & $\begin{array}{l}\text { The accumulation mode particles are considered to act as sponges for condensation or ad- } \\
\text { sorption of volatile materials. If the number of accumulation mode particles is significantly } \\
\text { reduced, there would not be enough surface area available for volatiles adsorption, and the } \\
\text { high concentration of gaseous volatiles would lead to the formation of a more pronounced } \\
\text { nucleation mode. }\end{array}$ \\
\hline [23] & $\begin{array}{l}\text { Bio-diesel has a very low sulfur content, so it is expected that fewer nuclei are formed. In } \\
\text { contrast, more small particles are formed with the probable explanation that less accumulation } \\
\text { particles are formed on which SOF and other particles can adsorb. }\end{array}$ \\
\hline$[24]$ & $\begin{array}{l}\text { The partitioning of particles takes place in the form of adsorption and condensation onto ex- } \\
\text { isting soot agglomerates or as nucleation of separate particles (droplets), usually between } 10 \\
\text { and } 30 \mathrm{~nm} \text { in diameter. Whether a separate nucleation particle is formed, as well as its size, } \\
\text { depends on a number of factors. Including the characteristics of the engine, the aftertreatment } \\
\text { systems, the fuel, the lubricant, the sample method, and the amount of soot that is present, } \\
\text { since this influences the competitive process of condensation and adsorption instead of nucle- } \\
\text { ation. }\end{array}$ \\
\hline [25] & $\begin{array}{l}\text { The formation of PM is not only due to the growth of elemental carbon soot, but also due to } \\
\text { the condensation of a considerable quantity of hydrocarbons. These hydrocarbons could form } \\
\text { particles or be adsorbed onto the surface of particle aggregates. }\end{array}$ \\
\hline [26] & $\begin{array}{l}\text { Bu20 had a noticeably higher number of nucleation mode particles than the other two fuels } \\
\text { tested. It is thought that this was due to the lower soot accumulation mode particles observed, } \\
\text { reducing nuclei adsorption, leading to higher numbers being observed in comparison to E20 } \\
\text { and ULG95. }\end{array}$ \\
\hline [27] & $\begin{array}{l}\text { The greater the particle surface area is, the greater the possibility of the surface absorption of } \\
\text { substances is, such as polycyclic aromatic hydrocarbons. The particle surface area has a direct } \\
\text { influence on the adsorption process and affects the mass concentration distribution and the } \\
\text { volume concentration distribution. The earlier timing results in a better fuel atomization such } \\
\text { that the combustion phase is correspondingly earlier, and the in-cylinder combustion tempera- } \\
\text { ture is higher, which may inhibit particle agglomeration, but results in higher nucleation mode } \\
\text { particle emissions. The proportion of diffusion combustion increases as the main injection } \\
\text { timing slows, and the generated soot particles can adsorb other fine particles. }\end{array}$ \\
\hline
\end{tabular}




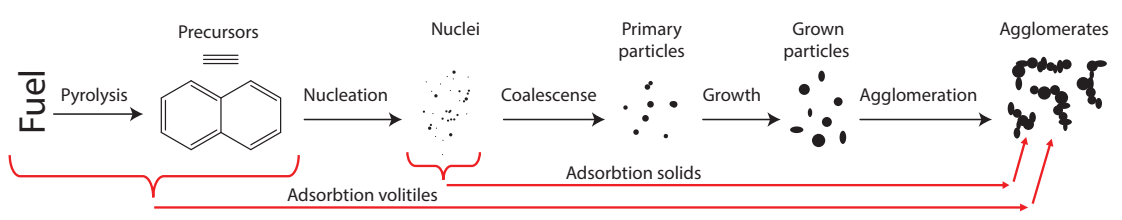

Figure 16: Schematic representation of particle adsorption theory

\subsection{Consequences in case a DPF is used}

EU emission legislation does not apply only to PM in terms of mass, but also to the total particle count $(\# / \mathrm{kWh})$. This count, however, considers only particles with a diameter in excess of $23 \mathrm{~nm}$.

Considering the trade-off between nucleation and accumulation particles presented earlier in this work, the consequence of decreasing the number of larger particles ( $>$ $23 \mathrm{~nm})$ is that the number of smaller particles $(<23 \mathrm{~nm})$ will increase, dramatically in some cases.

D'Anna et al. demonstrated recently that these small, non-legislated particles are in fact the most difficult to capture with a DPF [28]. While filter efficiency for particles greater than $23 \mathrm{~nm}$ is close to $100 \%$, this figure drops to below $80 \%$ for particles smaller than $23 \mathrm{~nm}$.

All this suggests that it may be best to calibrate engines such that a minimum number of larger particles is formed during the combustion cycle. Presumably, this will facilitate the majority of small particles to be adsorbed and subsequently more effectively captured in the DPF. 


\section{Conclusions}

Our main conclusion is that optima for both the classical PM-NO $\mathrm{P}_{x}$ and newly formulated accumulation-nucleation trade-off appear to occur concurrently. In other words, any effort to improve the gravimetric trade-off by means of engine calibration and/or fuel tailoring, is likely to yield dividends on the qualitative trade-off as well. Given the sheer breadth of operation conditions and fuel properties evaluated in this study, it would appear that this coincidence of optima, which might serve to guide engine calibrators and aftertreatment specialists towards the least harmful exhaust gas composition, is quite robust indeed.

Apart from this general observation, some more detailed conclusions may be drawn as well:

- For Euro I-V, there is a strong correlation between gravimetric PM emissions and the relative position on the accumulation-nucleation trade-off.

- For Euro VI, this apparent relationship is more ambiguous, given that near-zero levels in both modes are observed, but also excessively high levels of nucleation mode particles.

- Although $\mathrm{NO}_{x}$ does not correlate well with the general accumulation-nucleation trade-off, the aforementioned nucleation mode excesses are observed only at the highest $\mathrm{NO}_{x}$ levels (Euro I \& II). Conversely, at lower $\mathrm{NO}_{x}$ levels, mainly accumulation particles are measured.

- The apparent mutual exclusivity of nucleation and accumulation particle modes is likely the result of a competition for nuclei precursors (e.g., PAH) towards either nucleation or adsorption, respectively.

- In light of reportedly poor DPF efficiency for nucleation mode particles, it may be better to calibrate engine such that a minimum number of accumulation mode particles is formed, which might capture the greater majority of the nucleation mode particles more effectively via adsorption that would otherwise be the case in the DPF.

\section{Acknowledgments}

The authors gratefully acknowledge the financial support of SER-Brabant (New Energy House project), who was solely responsible for the finances and has not interfered with selecting Journal, content, conclusions or whatever. Furthermore, we would like to acknowledge our technical support team, Gerard van Hout, Theo de Groot and Hans van Griensven. 


\section{References}

[1] M. E. Gerlofs-Nijland, A. I. Totlandsdal, T. Tzamkiozis, D. Leseman, Z. Samaras, M. Låg, P. Schwarze, L. Ntziachristos, F. R. Cassee, Cell toxicity and oxidative potential of engine exhaust particles: Impact of using particulate filter or biodiesel fuel blend, Environmental Science \& Technology 47 (11) (2013) 59315938. doi:http://dx.doi.org/10.1021/es305330y.

[2] J. Bünger, J. Krahl, K. Baum, O. Schröder, M. Müller, G. Westphal, P. Ruhnau, T. G. Schulz, E. Hallier, Cytotoxic and mutagenic effects, particle size and concentration analysis of diesel engine emissions using biodiesel and petrol diesel as fuel, Archives of Toxicology 74 (8) (2000) 490-498. doi:http://dx.doi.org/10.1007/s002040000155.

[3] J. Krahl, G. Knothe, A. Munack, Y. Ruschel, O. Schröder, E. Hallier, G. Westphal, J. Bünger, Comparison of exhaust emissions and their mutagenicity from the combustion of biodiesel, vegetable oil, gas-to-liquid and petrodiesel fuels, Fuel 88 (6) (2009) 1064 - 1069. doi:http://dx.doi.org/10.1016/j.fuel.2008.11.015.

[4] A. D'Anna, Combustion-formed nanoparticles, Proceedings of the Combustion Institute 32 (1) (2009) 593 - 613. doi:http://dx.doi.org/10.1016/j.proci.2008.09.005.

[5] H. Burtscher, Physical characterization of particulate emissions from diesel engines: a review, Journal of Aerosol Science 36 (7) (2005) 896 - 932. doi:http://dx.doi.org/10.1016/j.jaerosci.2004.12.001.

[6] D. R. Tree, K. I. Svensson, Soot processes in compression ignition engines, Progress in Energy and Combustion Science 33 (3) (2007) 272 - 309. doi:http://dx.doi.org/10.1016/j.pecs.2006.03.002.

[7] D. B. Kittelson, Engines and nanoparticles: a review, Journal of Aerosol Science 29 (56) (1998) 575 - 588. doi:http://dx.doi.org/10.1016/S0021-8502(97)10037-4.

[8] M. M. Maricq, Chemical characterization of particulate emissions from diesel engines: A review, Journal of Aerosol Science 38 (11) (2007) 1079 - 1118. doi:http://dx.doi.org/10.1016/j.jaerosci.2007.08.001.

[9] M. D. Boot, On the manipulation of diesel particle nanostructure, M.Sc. report, Eindhoven University of Technology, (2005) WVT 2005.13.

[10] H. Omidvarborna, A. Kumar, D.-S. Kim, Recent studies on soot modeling for diesel combustion, Renewable and Sustainable Energy Reviews 48 (2015) 635 647. doi:http://dx.doi.org/10.1016/j.rser.2015.04.019.

[11] TSI Incorporated, Application note: Aerosol statistics lognormal dstributions and dn/dlogdp PR-001doi:http://www.tsi.com/engine-exhaust-particlesizer-spectrometer-3090. 
[12] R. Christian, F. Knopf, A. Jaschek, W. Schindler, Eine neue messmethodik der Bosch-zahl mit erhöhter empfindlichkeit, MTZ 54.

[13] W. F. Northrop, S. V. Bohac, J.-Y. Chin, D. N. Assanis, Comparison of filter smoke number and elemental carbon mass from partially premixed low temperature combustion in a direct-injection diesel engine, Journal of Engineering for Gas Turbines and Power 133(10). doi:http://dx.doi.org/10.1115/1.4002918.

[14] R. M. Montajir, T. Kawai, Y. Goto, M. Odaka, Thermal conditioning of exhaust gas: Potential for stabilizing diesel nano-particles, SAE Technical Paper: 200501-0187doi:http://dx.doi.org/10.4271/2005-01-0187.

[15] A. Fushimi, S. Hasegawa, K. Takahashi, Y. Fujitani, K. Tanabe, S. Kobayashi, Atmospheric fate of nuclei-mode particles estimated from the number concentrations and chemical composition of particles measured at roadside and background sites, Atmospheric Environment 42 (5) (2008) 949 - 959. doi:http://dx.doi.org/10.1016/j.atmosenv.2007.10.019.

[16] TSI Incorporated, Spec sheets: Engine exhaust particle sizer spectrometer model 3090.

URL http://www.tsi.com/engine-exhaust-particle-sizer-spectrometer-3090

[17] J. Reijnders, M. D. Boot, P. de Goey, Impact of aromaticity and cetane number on the soot- $\mathrm{NO}_{x}$ trade-off in conventional and low temperature combustion, Fuel 186 (2016) 24 - 34. doi:http://dx.doi.org/10.1016/j.fuel.2016.08.009.

[18] M. D. Boot, Biofuels from lignocellulosic biomass: innovations beyond bioethanol, Chapter 7: Benzenoids. John Wiley \& Sons, 2016.

[19] L. Zhou, M. D. Boot, B. H. Johansson, J. Reijnders, Performance of lignin derived aromatic oxygenates in a heavy-duty diesel engine, Fuel 115 (2014) 469 - 478. doi:http://dx.doi.org/10.1016/j.fuel.2013.07.047.

[20] I. S. Abdul-Khalek, D. B. Kittelson, F. Brear, Diesel trap performance: Particle size measurements and trends, SAE Technical Paper: 982599doi:http://dx.doi.org/10.4271/982599.

[21] D. B. Kittelson, M. Arnold, W. F. Watts, Review of diesel particulate matter sampling methods, University of Minnesota, Center for Diesel Research.

URL http: / / www . me. umn . edu/centers/cdr/reports/EPAreport3.pdf

[22] J. Desantes, V. Bermúdez, J. García, E. Fuentes, Effects of current engine strategies on the exhaust aerosol particle size distribution from a heavyduty diesel engine, Journal of Aerosol Science 36 (10) (2005) 1251 - 1276. doi:http://dx.doi.org/10.1016/j.jaerosci.2005.01.002.

[23] P. Tan, S. Ruan, Z. Hu, D. Lou, H. Li, Particle number emissions from a light-duty diesel engine with biodiesel fuels under transientstate operating conditions, Applied Energy 113 (2014) 22 - 31. doi:https://doi.org/10.1016/j.apenergy.2013.07.009. 
[24] B. Giechaskiel, M. Maricq, L. Ntziachristos, C. Dardiotis, X. Wang, H. Axmann, A. Bergmann, W. Schindler, Review of motor vehicle particulate emissions sampling and measurement: From smoke and filter mass to particle number, Journal of Aerosol Science 67 (2014) 48 - 86. doi:https://doi.org/10.1016/j.jaerosci.2013.09.003.

[25] Y. Luo, L. Zhu, J. Fang, Z. Zhuang, C. Guan, C. Xia, X. Xie, Z. Huang, Size distribution, chemical composition and oxidation reactivity of particulate matter from gasoline direct injection (GDI) engine fueled with ethanol-gasoline fuel, Applied Thermal Engineering 89 (2015) 647 - 655. doi:https://doi.org/10.1016/j.applthermaleng.2015.06.060.

[26] T. Lattimore, J. M. Herreros, H. Xu, S. Shuai, Investigation of compression ratio and fuel effect on combustion and PM emissions in a DISI engine, Fuel 169 (2016) 68 - 78. doi:https://doi.org/10.1016/j.fuel.2015.10.044.

[27] Y. Qian, Y. Zhang, X. Wang, X. Lu, Particulate matter emission characteristics of a reactivity controlled compression ignition engine fueled with biogas/diesel dual fuel, Journal of Aerosol Science 113 (2017) 166 - 177. doi:https://doi.org/10.1016/j.jaerosci.2017.08.003.

[28] M. Sirignano, A. D'Anna, Filtration and coagulation efficiency of sub$10 \mathrm{~nm}$ combustion-generated particles, Fuel 221 (2018) 298 - 302. doi:https://doi.org/10.1016/j.fuel.2018.02.107. 


\begin{tabular}{ll} 
AppendixA. & Nomenclature \\
\hline a & after \\
AMP & Accumulation Mode Particles \\
b & before \\
CA & Crank Angle \\
CAD & Crank Angle Degree \\
CN & Cetane number \\
CO & Carbon monoxide \\
CR & Compresion Ratio \\
EGR & Exhaust Gas Recirculation \\
FT & Fischer-Tropsch \\
GTL & Gas-to-Liquid \\
HC & Hydro Carbons \\
HD & Heavy Duty \\
HDDI & Heavy Duty Direct Injection \\
ID & Ignition Delay \\
IQT & Ignition Quality Tester \\
NMP & Nucleation Mode Particles \\
NO & Nitrogen Oxide(s) \\
PM & Particulate Matter \\
PPC & Partially Premixed Combustion \\
RoHR & Rate of Heat Release \\
rpm & rounds per minute \\
SCR & Selective Catalytic Reduction \\
SOC & Start of Combustion \\
SOI & Start of Injection \\
TDC & Top Dead Center \\
\hline &
\end{tabular}




\section{AppendixB. Diluters (Testo ViPR)}

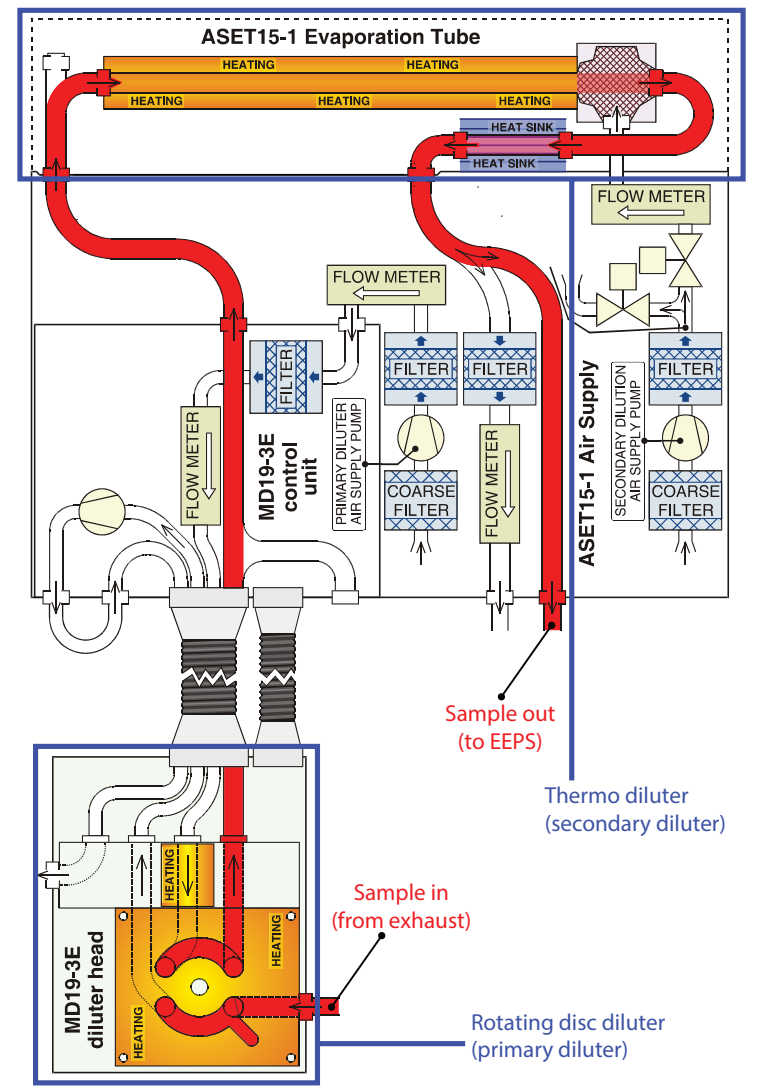

Figure B.1: Schematic diagram of the Testo ViPR [Reproduced with permission of Testo GmbH] 


\section{AppendixC. Particle matter correlations}

In Section 3.3.1, a correlation was observed between the PM Euro norm of any given data point and its associated position in the accumulation-nucleation trade-off (Figure 11).

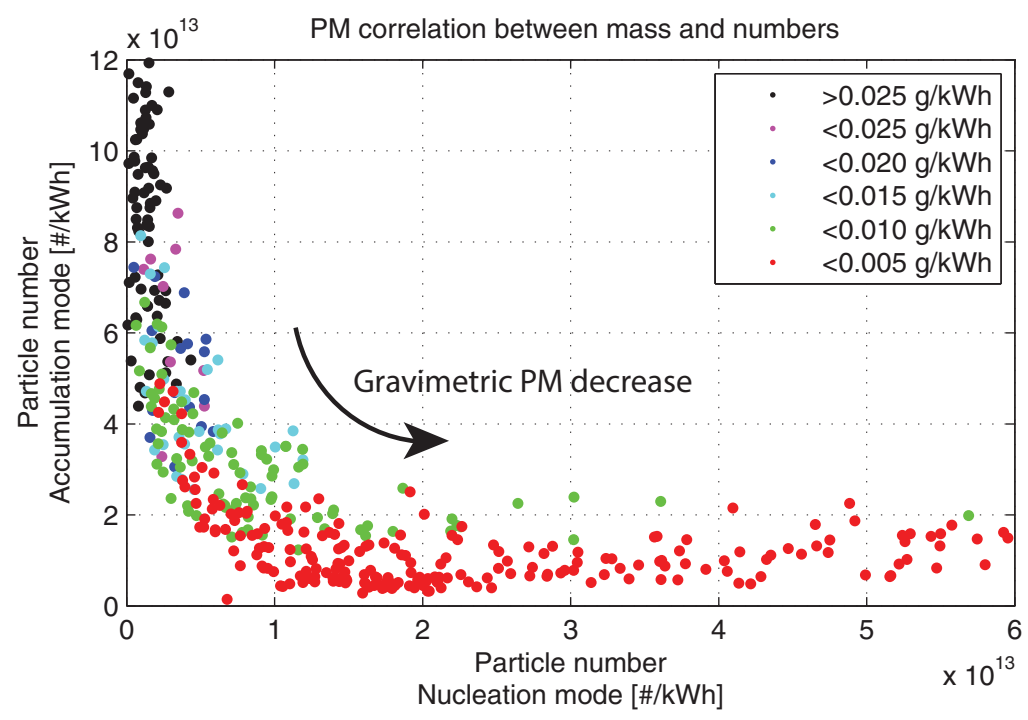

Figure C.2: PM mass and number correlations

In Figure C. 2 more details are shown on the relation of PM with respect to the mass and number concentrations. With decreasing mass, the accumulation mode numbers decrease as well. Below $0.010 \mathrm{~g} / \mathrm{kWh}$ (Euro VI norm), this number still decreases, but the number in nucleation mode starts to increase, as indicated by the red markers (below $0.005 \mathrm{~g} / \mathrm{kWh}$ ). 